\title{
GMR
}

\section{Hemerythrin is required for Aeromonas hydraphlia to survive in the macrophages of Anguilla japonica}

\author{
W.B. Zeng ${ }^{1,2}$, W.B. Chen ${ }^{1,2}$, Q.P. Yan ${ }^{1,2}$, G.F. Lin ${ }^{1,2}$ and Y.X. Qin ${ }^{1,2}$ \\ ${ }^{1}$ Fisheries College, Jimei University, Xiamen, Fujian, China \\ ${ }^{2}$ Key Laboratory of Healthy Mariculture for the East China Sea, \\ Ministry of Agriculture, Jimei University, Xiamen, Fujian, China \\ Corresponding author: Y.X. Qin \\ E-mail: yxqin@jmu.edu.cn \\ Genet. Mol. Res. 15 (2): gmr.15028074 \\ Received November 17, 2015 \\ Accepted January 15, 2016 \\ Published May 6, 2016 \\ DOI http://dx.doi.org/10.4238/gmr.15028074
}

\begin{abstract}
Survival in host phagocytes is an effective strategy for pathogenic microbes to spread. To understand the mechanisms of Aeromonas hydrophila survival within host macrophages, a library of mini-Tn10 transposon insertion mutants was constructed. The M85 mutant, whose survival in host macrophages was only $23.1 \%$ of that of the wild-type (WT) strain, was utilized for further study. Molecular analysis showed that a 756-bp open reading frame (ORF) (GenBank accession No. CP007576) in the M85 mutant was interrupted by miniTn10. This ORF encodes for a 183 -amino acid protein and displays the highest sequence identity (99\%) with the hemerythrin (Hr) protein of A. hydrophila subspecies hydrophila ATCC 7966. The survival of the WT, M85 mutant, and complemented M85 $(\mathrm{Hr})$ strains were compared in host macrophages in vitro, and the results showed that M85 exhibited defective survival, while that of M85 $(\mathrm{Hr})$ was restored. To investigate the possible mechanisms of $A$. hydrophila survival in host macrophages, the expression of $\mathrm{Hr}$ under hyperoxic and hypoxic conditions was evaluated. The results revealed that the expression of
\end{abstract}


this protein was higher under hyperoxic conditions than under hypoxic conditions, which indicates that $\mathrm{Hr}$ protein expression is sensitive to $\mathrm{O}_{2}$ concentration. Hydrogen peroxide sensitivity tests further suggested that the M85 mutant was more sensitive to oxidative stress than the WT and M85 ( $\mathrm{Hr})$ strains. Taken together, these results suggest that the $\mathrm{Hr}$ protein may act as an $\mathrm{O}_{2}$ sensor and as a detoxifier of reactive oxygen species, and is required for $A$. hydrophila survival within host macrophages.

Key words: Aeromonas hydrophila; Detoxifier; Hemerythrin; Macrophages

\section{INTRODUCTION}

It is well known that many clinical pathogenic microbes can survive in professional phagocytes, which makes it difficult for the host to eliminate them and allows them to spread (Wilson et al., 2011; Roop and Caswell, 2013). For these reasons, survival in host phagocytes is an important factor in the virulence of pathogens (De Herdt et al., 1995), and thus increasing numbers of studies have focused on the survival mechanisms of some clinically important pathogenic microbes, such as Salmonella species, Mycobacterium tuberculosis, and Legionella pneumophila (Finlay and Falkow, 1997; Kumar and Valdivia, 2009). Understanding the survival mechanisms of bacteria greatly promotes the identification of host markers and drug targets for therapeutic interventions to control the infectious process (Forst, 2010).

However, only a few fish pathogens have been studied for their persistence and survival in host phagocytes (Ryckaert et al., 2010; Baumgartner et al., 2014), and even fewer studies on the mechanisms of their survival in phagocytes have been performed. Due to the spread and adverse effects of fish diseases, it is urgent to elucidate how fish pathogens persist and survive in their host phagocytes.

Aeromonas hydrophila is a Gram-negative facultative anaerobe that is ubiquitous in aquatic environments (Janda and Abbott, 2010). This bacterium is not only widely considered a major fish and amphibian pathogen, but also causes gastroenteritis, cellulitis, and other diseases in humans (Liu, 2009; Chao et al., 2013). Our previous studies revealed that A. hydrophila can invade and survive in host Anguilla japonica macrophages in vitro (Qin et al., 2014). However, knowledge on the mechanisms of $A$. hydrophila invasion and survival in these host macrophages remains limited. Therefore, the aim of the current study was to identify crucial genes and proteins that are critical to the survival of $A$. hydrophila in host phagocytes.

\section{MATERIAL AND METHODS}

\section{Bacterial strains and growth conditions}

The bacterial strains and plasmids used in this study are presented in Table 1. Escherichia coli was grown in Luria-Bertani (LB) broth at $37^{\circ} \mathrm{C}$, and A. hydrophila was grown at $28^{\circ} \mathrm{C}$ in Trypticase Soy broth (TSB). When required, antibiotics were supplemented at the following concentration: kanamycin at $100 \mathrm{mg} / \mathrm{mL}\left(\mathrm{Km}^{100}\right)$, ampicillin at $50 \mathrm{mg} / \mathrm{mL}\left(\mathrm{Ap}^{50}\right)$, streptomycin at $50 \mathrm{mg} / \mathrm{mL}\left(\mathrm{Sm}^{50}\right)$, and chloromycetin at $25 \mathrm{mg} / \mathrm{mL}$. When necessary, the 
density of bacteria was adjusted according to the optical density at $550 \mathrm{~nm}\left(\mathrm{OD}_{550}\right)$. All of the medium components were purchased from Oxoid (UK), and the antibiotics were purchased form BBI (China).

\begin{tabular}{|c|c|c|}
\hline Strain or plasmid & Characteristic(s) & Source \\
\hline \multicolumn{3}{|l|}{ Strain } \\
\hline \multicolumn{3}{|c|}{ Aeromonas hydrophila } \\
\hline WT & wild-type (WT) strain $\left(\mathrm{Sm}^{\mathrm{R}}\right)$ & (Guo, 2006) \\
\hline$\overline{\mathrm{M} 01 \sim \mathrm{M} 102}$ & mini-Tn10Km insertion mutant $\left(\mathrm{Sm}^{\mathrm{R}} \mathrm{Km}^{\mathrm{R}}\right)$ & This study \\
\hline $\mathrm{M} 85$ & $H r:: \operatorname{mini}-\mathrm{Tn} 10 \mathrm{Km}\left(\mathrm{Sm}^{\mathrm{R}} \mathrm{Km}^{\mathrm{R}}\right)$ & This study \\
\hline$\overline{\mathrm{M} 85(\mathrm{Hr})}$ & M85 complemented with pACYC184- $H r\left(\mathrm{Sm}^{\mathrm{R}} \mathrm{Km}^{\mathrm{R}} \mathrm{Cm}^{\mathrm{T}}\right)$ & This study \\
\hline \multicolumn{3}{|l|}{ Escherichia coli } \\
\hline SM10 & $\begin{array}{l}\text { thi thr leu tonA lacY supE recA } \mathrm{RP} 4-2-\mathrm{Tc}:: \mathrm{Mu}:: \mathrm{Km}\left(\lambda \text { pir) } \mathrm{F}^{-}, \varphi \text { 80dlacZ } \Delta \mathrm{M} 15,\right. \\
\Delta(\text { lacZYA-argF)U169, deoR, recAl }\end{array}$ & (Herrero et al., 1990) \\
\hline E. coli $\mathrm{DH} 5 \alpha$ & endA1, hsdR17 $\left(r K^{-}, m K^{+}\right)$, phoA, supE44, $\lambda$, thi-1, gyrA96, relA1 & TaKaRa \\
\hline Plasmid & Characteristic(s) & Source \\
\hline pMD18-T & Cloning vector $\left(\mathrm{Ap}^{\mathrm{R}}\right)$ & TaKaRa \\
\hline $\mathrm{pLOF} / \mathrm{Km}$ & Tn10-based delivery plasmid with $\left(\mathrm{Km}^{\mathrm{R}} \mathrm{Ap}^{\mathrm{R}}\right)$; & (Herrero et al., 1990) \\
\hline $\mathrm{pACYC} 184$ & $\left(\mathrm{Cm}^{\mathrm{R}} \mathrm{Tc}^{\mathrm{R}}\right)$ & Provided by Prof. Nie \\
\hline pACYC184-hr & $\begin{array}{l}\text { pACYC184 derivative containing 740-bp fragment of hemerythrin gene }(\mathrm{Hr}) \\
\text { putative promoter and } \mathrm{ORF}\left(\mathrm{Cm}^{\mathrm{R}}\right)\end{array}$ & This study \\
\hline
\end{tabular}

\section{Macrophage isolation and in vitro infection}

Healthy A. japonica were purchased from an aquaculture farm. Monolayers of $A$. japonica macrophages were prepared as previously described (Secombes, 1990; do Vale et al., 2003), with minor modifications. The heads of the kidneys were removed and pooled under aseptic conditions. The tissues were then pushed through sterile $100-\mu \mathrm{m}$ nylon mesh into Leibovitz-15 medium (L-15, Israel) containing $10 \mathrm{IU} / \mathrm{mL}$ heparin, $100 \mathrm{IU} / \mathrm{mL}$ streptomycin/ penicillin $(\mathrm{S} / \mathrm{P})$, and $2 \%$ fetal calf serum (FCS). The cell suspensions were layered onto a $34 / 51 \%$ discontinuous Percoll (Amersham Pharmacia Biotech, UK) density gradient with a syringe and centrifuged at $400 \mathrm{~g}$ for $30 \mathrm{~min}$ at $4^{\circ} \mathrm{C}$. The band of cells above the $34 / 51 \%$ interface was collected and washed twice with L-15 medium. Subsequently, viable cells were counted using a Bürker counting chamber with trypan blue dye exclusion. Then, the cell suspension was adjusted to $10^{7}$ cells $/ \mathrm{mL}$ in L-15 medium containing $10 \% \mathrm{FCS}$, and $1 \mathrm{~mL}$ was added to each well of a 6-well culture plate (Nunc, China). After incubation at $28^{\circ} \mathrm{C}$ for $4 \mathrm{~h}$, the non-adherent cells were removed by washing with L-15 medium and the remaining monolayer was incubated at $28^{\circ} \mathrm{C}$ in L-15 medium with $10 \%$ FCS. Next, $1 \mathrm{~mL}$ bacterial suspension at a multiplicity of infection of 100 was added to each well. After incubation at $28^{\circ} \mathrm{C}$ for 1 $\mathrm{h}$, the macrophages were washed twice with cold phosphate-buffered saline (PBS), and the cells were resuspended in $2 \mathrm{~mL}$ PBS. Then, the cell suspensions were treated with $250 \mathrm{mg} /$ $\mathrm{mL}$ gentamycin for $20 \mathrm{~min}$ at $4^{\circ} \mathrm{C}$ to eliminate extracellular bacteria, and then washed twice. The supernatant was withdrawn and tested for sterility. The cells were resuspended in fresh L-15 medium with $10 \mathrm{IU} / \mathrm{mL}$ heparin, $100 \mathrm{IU} / \mathrm{mL} \mathrm{S} / \mathrm{P}$, and $10 \% \mathrm{FCS}$, and this time point was denoted as time zero. After several hours of incubation, the cells were centrifuged for $5 \mathrm{~min}$ at $100 \mathrm{~g}$ at $28^{\circ} \mathrm{C}$, and $1 \mathrm{~mL}$ sterile distilled water was added for $30 \mathrm{~min}$ to lyse the cells. The number of bacteria released was determined by plating appropriate dilutions on TSA plates as previously described (Larsen and Boesen, 2001; Ryckaert et al., 2010). 


\section{Mini-Tn10 mutagenesis and isolation of mutants defective in survival within macrophages}

Mini-Tn10 random mutagenesis was carried out using a modification of a filter mating technique developed by Herrero et al. (1990). Briefly, A. hydrophila was mated with the E. coli $\mathrm{Sm} 10$ strain $(\mathrm{pLOFKm})$ containing the mini-Tn 10 transposon. Aliquots $(50 \mu \mathrm{L})$ from overnight cultures of the $E$. coli Sm10 donor and A. hydrophila recipient strains were mixed at a ratio of $1: 4$ in LB broth. The cells were filtered through a $0.22-\mathrm{mm}$ pore filter and incubated for $4 \mathrm{~h}$ at $28^{\circ} \mathrm{C}$ on TSA plates containing $3 \mathrm{mM}$ isopropyl $\beta$-D-1-thiogalactopyranoside (IPTG) (Sangon, China). The filters were eluted with $1 \mathrm{~mL}$ TSB and incubated at $28^{\circ} \mathrm{C}$ for $24 \mathrm{~h}$. Approximately $100 \mu \mathrm{L}$ cells were spread onto TSA plates supplemented with $\mathrm{Km}^{100}$ and $\mathrm{Sm}^{50}$ to select for $A$. hydrophila mutants containing the mini-Tn 10 transposon. To analyze the intracellular survival of the $A$. hydrophila mutants, single colonies were selected according to the infection assay described above.

\section{Southern blot analysis}

Southern blot analysis was performed according to the procedure described by Rock and Nelson (2006), with some modifications. Briefly, total genomic DNA from wild-type (WT) $A$. hydrophila and mutant $A$. hydrophila was extracted using a bacterial genomic DNA extraction kit (TaKaRa, Japan) and digested overnight with the restriction enzyme SacI (TaKaRa), which does not cut within the transposon. Then, the fragments were separated by agarose gel electrophoresis and transferred to a nylon membrane as described (Larsen and Boesen, 2001). The membranes were probed with a digoxigenin (DIG)-dUTP-labeled probe (Roche, Switzerland) for the mini-Tn10 transposon. The $\mathrm{Km}^{\mathrm{R}}$ gene probe that is able to recognize the mini-Tn 10 transposon was generated by polymerase chain reaction (PCR) amplification of a 176-bp region of the $\mathrm{Km}^{\mathrm{R}}$ gene using the primer pair Km3: 5'-CGGGGATCGCAGTGG-3' and Km4: 5'-TGGGAAGCCCGATGC-3', and the DIG-PCR Probe Synthesis Kit (Roche). After hybridization at $42^{\circ} \mathrm{C}$ for $16 \mathrm{~h}$, immunological detection of specific fragments was performed using the DIG Detection Kit (Roche).

\section{Molecular analysis of the mutants}

Thermal asymmetric interlaced-PCR (TAIL-PCR) was used to acquire the DNA sequence flanking the transposon mutants following published procedures (Rock and Nelson, 2006). The arbitrary primer was supplied by the Genomic Walking Kit (TaKaRa), and the nested primers specific to the transposon are listed in Table 2. Among the nested primers, LSP4, LSP5, and LSP6 along with RSP4, RSP5, and RSP6 were used to amplify upstream and downstream sequences flanking the transposon. The PCR products were purified with a Gel Extraction Kit (Omega, USA), and the purified fragments were ligated into the plasmid pMD18-T (TaKaRa) and sequenced. The DNA sequences were aligned against those in the NCBI database with BLASTn and other softwares including ClustalW and MegAlign (DNAStar). 
Table 2. Specific primers used for TAIL-PCR.

\begin{tabular}{l|l}
\hline Primer & Sequence \\
\hline LSP4 & 5'-ATGCTTGATGGTCGGAAGAGGC-3' \\
\hline LSP5 & 5'-CATCGGGCTTCCCATACAATCG-3' \\
\hline LSP6 & 5'-ATTATCGCGAGCCCATTTATACCC-3' \\
\hline RSP4 & 5'-CCTGTTGAACAAGTCTGGAAAGAAATG-3' \\
\hline RSP5 & 5'-GATCTTGCCATCCTATGGAACTG-3' \\
\hline RSP6 & 5'-TTACGCTGACTTGACGGGACGG-3' \\
\hline
\end{tabular}

\section{Complementation}

The hemerythrin (Hr) gene was amplified using the forward primer Hr-EcoRV: 5'-GATATCAGCCCCATCAACTGGCACTCGGTC-3' and the reverse primer Hr-HA: 5' - TCA C TA GA GGCTA GCATA ATCA GGA A CATCATA CGGATA GGAA GA GAGCGGCAGCGACAGG-3', where the EcoRV restriction enzyme site is underlined, and the SalI restriction enzyme site in the pMD18-T plasmid and the HA-tag sequence are italicized. The PCR product was digested by EcoRV and SalI (TaKaRa) and ligated into the pACYC184 plasmid digested by the same enzymes to produce a recombinant plasmid pACYC184-Hr. Then, pACYC184-Hr was introduced into the mutant M85 by electroporation. The complementary M85 strain (Hr) was selected on chloromycetin plates. To confirm the expression of the fusion protein, western blot analysis was performed using an anti-HA-tag antibody (Sigma, USA) according to the method described by Green and Sambrook (2012). Briefly, total protein from the bacterial cells was obtained by heating at $100^{\circ} \mathrm{C}$ for $5 \mathrm{~min}$ in lysis buffer. Then, lysates from each sample $(20 \mu \mathrm{L})$ were separated on a $12 \%$ gel and transferred to a PVDF membrane (GE Healthcare, USA). Then, after blocking with $1 \%$ skim milk in PBS, the membrane was incubated with a 1:3000 dilution of an anti-HA-tag antibody. After washing with PBS, the membrane was incubated with a 1:5000 dilution of goat anti-rabbit horseradish peroxidase-conjugated secondary antibody (Sigma). Then, the chromomeric substrate-3'3diaminobenzidine was added, and the membrane was imaged using a digital camera.

\section{Analysis of biological characteristics}

\section{Invasion and survival}

WT A. hydrophila, M85, and M85 (Hr) survival in macrophages in vitro was evaluated with the method described above, except that the incubation times of the cell suspensions were 0 and $1 \mathrm{~h}$ at the last step.

\section{Motility assay}

LB broth with $0.35 \%$ agar was used to characterize the swimming motility of the WT, M85, and M85 ( $H r)$ strains. The overnight cultures were adjusted to the same optical density and equal numbers $\left(10^{8}\right)$ of CFU were added to test tubes filled with semi-soft medium and incubated at $28^{\circ} \mathrm{C}$. Single colonies of bacteria were added to test tubes filled with semi-soft medium and incubated at $28^{\circ} \mathrm{C}$ for $\sim 10 \mathrm{~h}$ to observe their motility. 


\section{RNA extraction and reverse transcription (RT)-PCR assays}

TSB $(100 \mathrm{~mL})$ without antibiotics was inoculated with $1 \mathrm{~mL}$ bacterial suspension containing $10^{8} \mathrm{CFU} / \mathrm{mL}$ and incubated at $28^{\circ} \mathrm{C}$ under high- and low-oxygen concentrations provided by rotation speeds of 200 and $20 \mathrm{rpm}$, respectively. Moreover, the low-oxygen Erlenmeyer flask was sealed with a seal membrane. Total RNA from the WT strain was isolated with TRIzol Reagent (Invitrogen, USA) according to manufacturer instructions after incubation for $0,5,10,20$, and $30 \mathrm{~h}$. Total RNA from each sample was reverse transcribed using the TransScript One-Step gDNA Removal and cDNA Synthesis Supermix (Transgene, China). Quantitative RT-PCR was performed on the five WT cDNA samples. The amplification reaction mix contained 1X SYBR Green PCR Supermix (Roche), specific primer pairs (see Table 3), and $1 \mu \mathrm{L}$ of the reverse transcription reaction product. The amplification conditions were as follows: $95^{\circ} \mathrm{C}$ for $3 \mathrm{~min}$ followed by 40 cycles of $95^{\circ} \mathrm{C}$ for $20 \mathrm{~s}, 58^{\circ} \mathrm{C}$ for $20 \mathrm{~s}$, and $72^{\circ} \mathrm{C}$ for $20 \mathrm{~s}$. Melting curves were generated after amplification. Data were collected with the StepOnePlus RT PCR System (Applied Biosystems, USA). Each transcript was analyzed in three biological replicates, and expression levels were normalized to the reference gene 16sRNA. The samples at high-oxygen concentration were the experimental group and the samples at low-oxygen concentration were the control group.

Table 3. Specific primers used for RT-PCR.

\begin{tabular}{|c|c|}
\hline Primer & Sequence \\
\hline $\mathrm{HrF}$ & 5'-ATCACCATCCGAAGG-3' \\
\hline HrR & 5'-ACGCCAATCATCCTC-3' \\
\hline 16sRNA F & 5'-GGGGAGTACGGTCGCAAGAT-3' \\
\hline 16sRNA R & 5'-CGCTGGCAAACAAGGATAAGG-3' \\
\hline
\end{tabular}

\section{Sensitivity to oxidative stress}

The oxidative stress sensitivity assay was performed according to methods described by Yamamoto et al. (1996). Briefly, bacterial cultures were grown to the exponential phase overnight in TSB at $28^{\circ} \mathrm{C}$, harvested, resuspended in PBS, and adjusted to the same optical density. Bacterial cultures were then treated with $8.8 \mathrm{mM}$ hydrogen peroxide for $1 \mathrm{~h}$, and then the samples before and after treatment were diluted and plated on TSA. Viable counts were determined after incubation of the plates for $24 \mathrm{~h}$ at $28^{\circ} \mathrm{C}$.

\section{RESULTS}

\section{Isolation of mutants defective in survival within macrophages}

A library of mini-Tn 10 transposon insertion mutants of A. hydrophila was constructed, and 102 mutants from this library were evaluated for their survival in the macrophages of A. japonica. Figure 1 shows that $\sim 1.3 \times 10^{5} \mathrm{CFU} / \mathrm{mL}$ of the WT bacteria survived in the macrophages, while only $\sim 3 \times 10^{4} \mathrm{CFU} / \mathrm{mL}$ of the M85 mutant survived, which indicates that M85 exhibited a $76.9 \%$ reduction in survival capability when compared with that of the WT strain $(\mathrm{P}<0.01)$. Therefore, this mutant was selected for further study. 


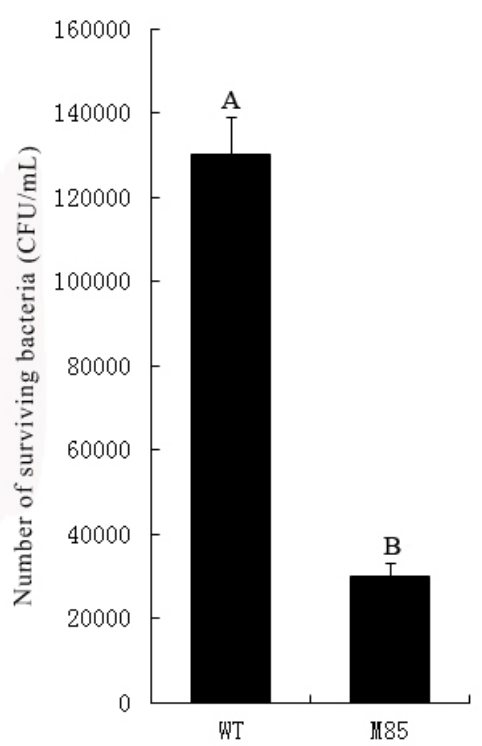

Figure 1. M85 mutant and WT strain survival in macrophages. Different letters are significantly different when compared by ANOVA $(\mathrm{P}<0.01)$.

\section{Southern blot analysis of the WT and mutant strains}

Southern blot analysis of SacI-digested genomic DNA of the M85 mutant probed with the kanamycin-resistance cassette showed that only a single band was present in the M85 mutant and the pLOFKm-positive control, and no signal was detected in the WT strain (Figure 2). This result demonstrates that the reduction in survival capability of the M85 mutant was likely caused by the mini-Tn 10 transposon insertion, and this was due to a singly mini- $\operatorname{Tn} 10$ transposon insertion in the chromosome of this mutant.

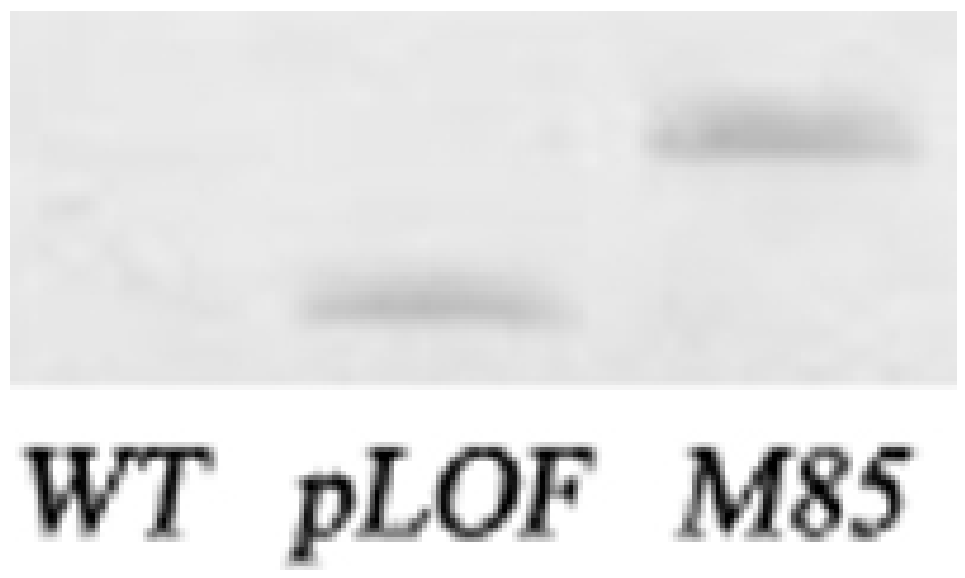

Figure 2. Insertion of the mini- $\mathrm{Tn} 10 \mathrm{Km}$ transposon in the M85 mutant. 


\section{Amino acid sequence of the M85 mutant}

TAIL-PCR was used to amplify the gene flanking the mini-Tn 10 transposon that was inserted into the mutant M85 genome. The PCR products of the upstream and downstream sequences were purified using a gel extraction kit, and cloned into the pMD18-T plasmid for DNA sequencing. Sequence analysis (Figure 3) showed that there was a 756-bp sequence of the M85 mutant containing the mini-Tn10 transposon. This sequence contained an openreading frame (ORF) of $549 \mathrm{bp}$. This ORF encodes a 183-amino acid residue protein with a predicted molecular mass of $21.322 \mathrm{kDa}$, and displays the highest sequence identity $(99 \%)$ with the $H r$ gene of the $A$. hydrophila subspecies hydrophila ATCC 7966 (GenBank accession No. CP000462). A conserved domain search (through the NCBI database) revealed that this protein had the following conserved feature residue pattern: H-H-X-E--H-E. Two iron ions can bind to this protein via the following seven conserved amino acid residues: five histidine, one glutamate, and one aspartate (Stenkamp, 1994; French et al., 2008).

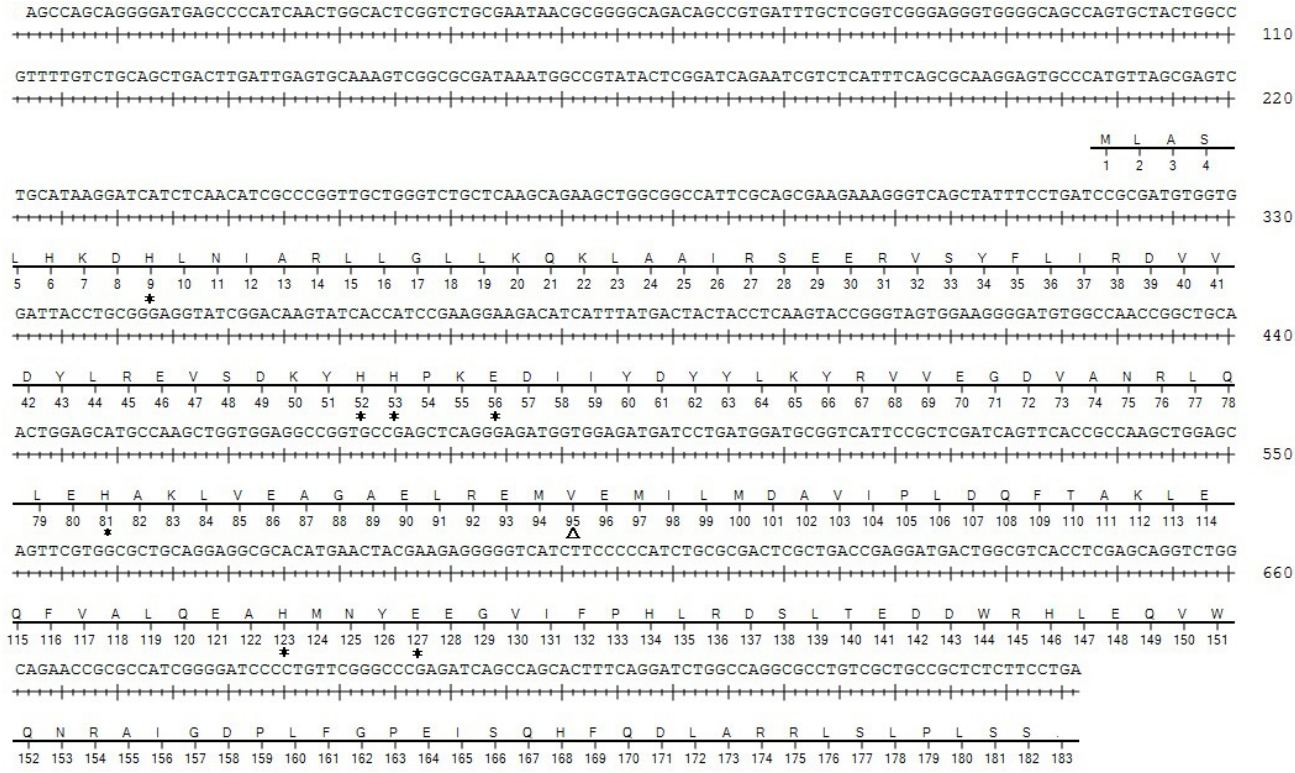

Figure 3. ORF nucleotide and corresponding amino acid sequences. The amino acids are indicated below the nucleotide sequence. Conserved amino acid residues are indicated with asterisks below them. The Tn10 insertion site is indicated with a triangle icon below it $(\Delta)$.

\section{Complementation}

The western blot analysis (Figure 4) showed that there was a distinct band with a molecular weight of approximately $21 \mathrm{kDa}$ detected in the M85 $(\mathrm{Hr})$ complementation strain, which suggests that the $\mathrm{Hr}$ protein was expressed in this strain. 


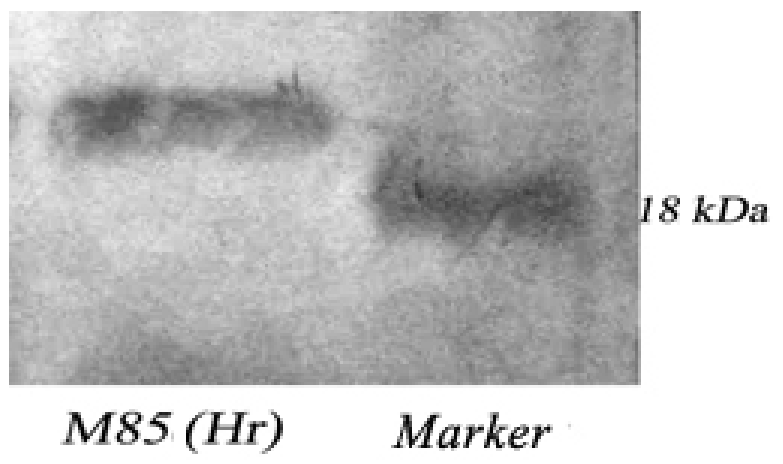

Figure 4. Hemerythrin expression in the M85 $(\mathrm{Hr})$ complementation strain.

\section{Bacterial survival in macrophages in vitro}

The data presented in Figure 5 show that only $\sim 3.49 \%$ of invasive M85 cells survived after $1 \mathrm{~h}$ of infection, while the survival rates of WT and M85 $(\mathrm{Hr})$ were 10.9 and $15.7 \%$, respectively. There was no significant difference between the survival rates of the WT and M85 $(\mathrm{Hr})$ strains, while the survival rate of M85 was significantly lower than those of both the WT and M85 (Hr $)$ complementation strains $(\mathrm{P}<0.05)$. Thus, the introduction of PACYC184$\mathrm{Hr}$ could compensate for the decline in survival of M85 in macrophages.

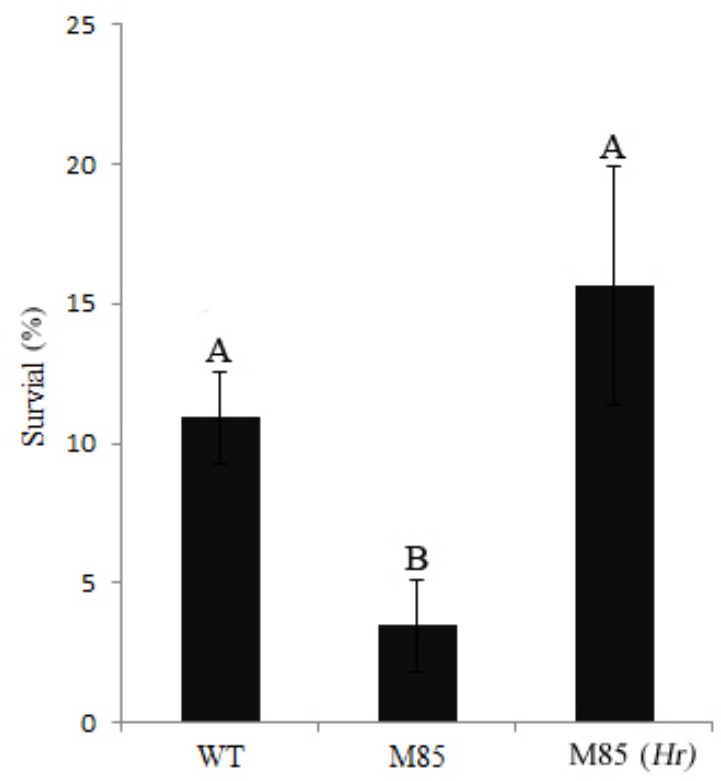

Figure 5. Survival rate of the WT, M85, and M85 $(\mathrm{Hr})$ strains after $1 \mathrm{~h}$ of infection in macrophages. Different letters are significantly different when compared by ANOVA $(\mathrm{P}<0.01)$. 


\section{Bacteria motility}

The results presented in Figure 6 show that all three strains exhibited diffuse growth in semi-soft medium, which indicates that the mutation of the $\mathrm{Hr}$ gene had no impact on the motility of A. hydrophila, and moreover that the reduction in survival capability of the M85 mutant was not attributed to bacterial motility.

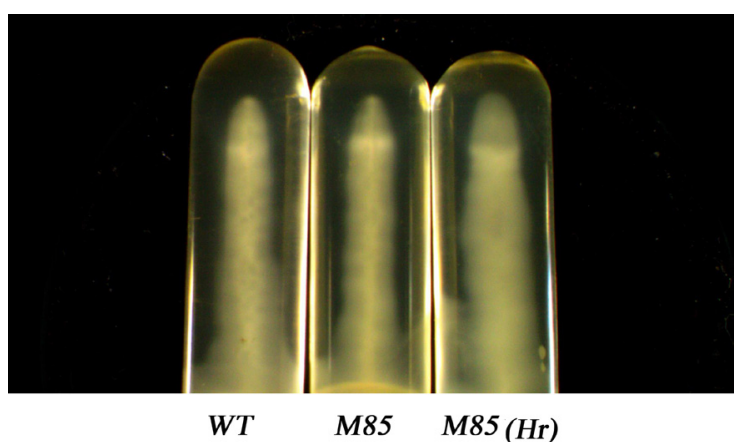

Figure 6. Motility of the WT, M85, and M85 (Hr) strains in semi-soft medium.

\section{Influence of oxygen on the expression of $\mathrm{Hr}$}

To investigate the relationship between $\mathrm{Hr}$ expression and oxygen concentration, the expression of $\mathrm{Hr}$ was evaluated by RT-PCR. The results shown in Figure 7 demonstrate that the expression of $\mathrm{Hr}$ in the WT strain under hyperoxic conditions was 3.69 times higher than that under hypoxic conditions after $5 \mathrm{~h}$ of incubation. However, with increased incubation time, $\mathrm{Hr}$ expression was restored to similar levels under the different oxygen concentrations.

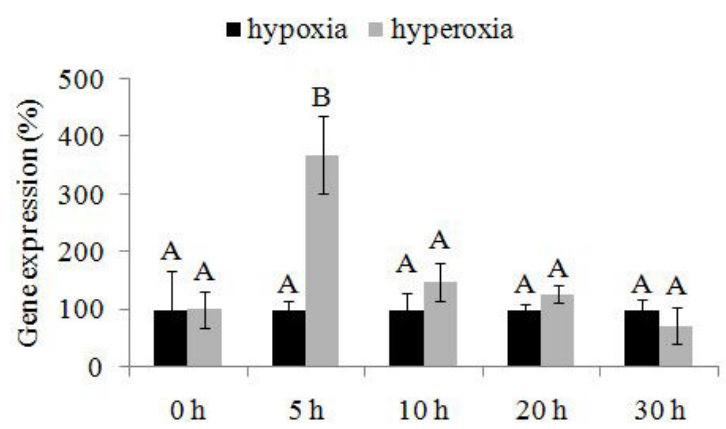

Figure 7. Expression of $\mathrm{Hr}$ at high and low oxygen concentrations was determined by RT-PCR. Different letters are significantly different when compared by ANOVA $(\mathrm{P}<0.01)$.

\section{Hydrogen peroxide sensitivity test}

The data shown in Figure 8 demonstrate that the survival rate of M85 under $\mathrm{H}_{2} \mathrm{O}_{2}$ stress $(2.8 \%)$ was significantly lower than those of WT and M85 $(\mathrm{Hr})$, which were 8.5 and $6.9 \%$, respectively $(\mathrm{P}<0.05)$. These results suggest that mutagenesis in the $H r$ domain of $A$. 
hydrophila may significantly enhance bacterial sensitivity to $\mathrm{H}_{2} \mathrm{O}_{2}$ stress, and this may prevent survival in macrophages.

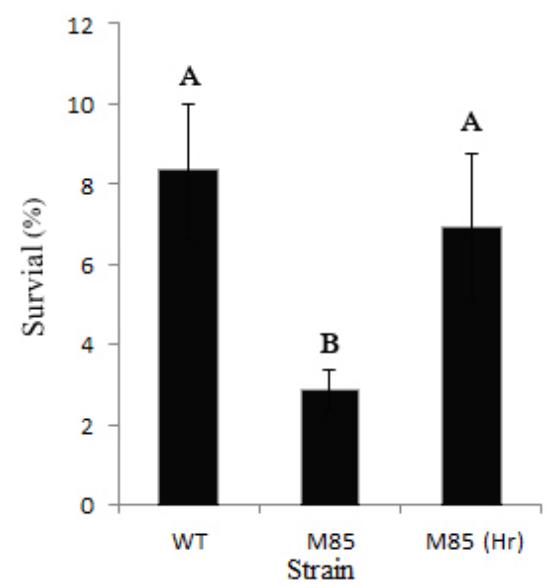

Figure 8. Survival rate of the WT, M85, and M85 ( $\mathrm{Hr}$ ) strains after exposure to $8.8 \mathrm{mM}$ hydrogen peroxide for 1 h. Different letters are significantly different when compared by ANOVA $(\mathrm{P}<0.01)$.

\section{DISCUSSION}

In the current study, we found that the ability of $A$. hydrophila to survive in host macrophages was significantly decreased after $\mathrm{Hr}$ gene disruption. Moreover, the complement strain that contained the $\mathrm{Hr}$ gene was able to recover its survival in host macrophages. These results indicated that the $\mathrm{Hr}$ protein may play a vital role in the intracellular survival of $A$. hydrophila.

When pathogenic microbes invade the host cell, the interaction between the pathogen and the host's innate defense system begins. This pathogen-host interaction is complicated, but the mechanisms of the survival of many obligate intracellular pathogens have been increasingly elucidated (Garcia-del Portillo and Finlay, 1995; Seider et al., 2010; Roop and Caswell, 2013). The strategies used by pathogens to survive in host macrophages include damaged phagocytosis and escape, counteracting the oxidative burst, and inhibiting phagosome maturation or acidification (Garcia-del Portillo and Finlay, 1995; Seider et al., 2010). However, knowledge regarding the intracellular survival of certain non-obligate intracellular bacteria is lacking.

In the current study, we found that the motility of the M85 mutant was not impaired compared with that of the WT strain. Interestingly, it has been reported that motility is required for $A$. hydrophila to invade and survive in macrophages, as it contributes to the escape from phagosomes or lysosomes into the cytoplasm (Qin et al., 2014). Sano et al. (2007) also reported that Salmonella enterica use flagella to escape from host macrophages. Based on our results, we speculate that the impaired survival ability of the M85 mutant in macrophages did not depend on bacterial flagella and motility.

It is well known that $\mathrm{Hr}$ is one of the three major respiratory proteins capable of reversibly binding dioxygen (Stenkamp, 1994; Mizoguchi and Lippard, 1998). This protein has only been found in certain marine invertebrates, such as those in the phyla Sipunculida. Other than oxygen transport, the possible functions of $\mathrm{Hr}$ in annelids have been proposed to include cadmium binding, antibacterial actions, and immunoprotection (Bailly et al., 2008). In recent 
years, an increasing amount of research has found that Hr-like proteins are widely distributed in prokaryotes. Specifically, approximately one fourth of the $\mathrm{Hr}$ domains were identified as $\mathrm{N}$ - or C-terminal domains of chimeric, chemotactic gene regulators, and the putative functions of these proteins also include the binding of oxygen as a sensor and the binding of reactive oxygen species (ROS) as a detoxifier (Bailly et al., 2008; French et al., 2008).

In the current study, we found that a single-domain $\mathrm{Hr}$ mutation decreased the ability of $A$. hydrophila to survive in macrophages, and that the expression of the $\mathrm{Hr}$ protein was repressed in a hypoxic environment. These results indicate that the Hr protein may act as an oxygen biosensor to reprogram transcription to adapt to the harsh internal environment of the phagocyte. This is consistent with the results of recent research that showed that Hr-like proteins are emerging as $\mathrm{O}_{2}$ and iron sensors in both bacteria and humans (Taabazuing et al., 2014). For example, the methyl-accepting chemotaxis protein from Desulfovibrio vulgaris, DcrH-Hr, contains an Hr domain that acts as an oxygen sensor (Isaza et al., 2006). Furthermore, mice lacking the F-box and leucine-rich repeat protein (FBXL5), which possesses an N-terminal Hr domain, failed to sense intracellular iron and $\mathrm{O}_{2}$ levels (Ruiz and Bruick, 2014).

It has been reported that intracellular $\mathrm{O}_{2}$ concentration is often less than $10 \%$ of the ambient value in animal tissues (Semenza, 2012), and that the mitochondrial electron transport chain produces excess ROS such as $\mathrm{H}_{2} \mathrm{O}_{2}$ under acute hypoxic conditions (Alfadda and Sallam, 2012). Therefore, the bacteria that invade host macrophages must respond to acute changes in $\mathrm{O}_{2}$ concentration and increased ROS levels to survive. Therefore, we speculate that the Hr protein may have the following functions: a) it may act as an $\mathrm{O}_{2}$ sensor to adapt to various environments, and b) it may confer protection against oxidative stress by repairing iron-sulfur clusters.

The $\mathrm{Hr}$ protein senses reductions in $\mathrm{O}_{2}$ concentration after bacteria invade host macrophages, by which it then affects respiratory efficiency by reducing oxygen transfer to the terminal respiratory apparatus, which has a similar function to that of Vitreoscilla hemoglobin (Ramandeep et al., 2001), thus ultimately affecting gene translation and protein expression. At the same time, the $\mathrm{Hr}$ protein also plays a role in detoxification to protect bacteria from ROS damage. Oxidative stress produced by macrophages is an important innate defense mechanism, and can involve both ROS and reactive nitrogen species (Fang, 2004). This stress can rapidly damage the proteins of pathogens that contain iron-sulfur clusters, which participate in a wide range of biological processes, including those of electron transfer chains and gene regulation (Beinert et al., 1997; Johnson et al., 2005). In the current study, we found that a mutation in the $\mathrm{Hr}$ gene of $A$. hydrophila results in increased sensitivity to $\mathrm{H}_{2} \mathrm{O}_{2}$. Justino et al. (2007) and Vine et al. (2010) also reported that the E. coli Hr-like protein $\mathrm{YtfE}$, which has the same conserved domain as $\mathrm{Hr}$, confers protection against $\mathrm{H}_{2} \mathrm{O}_{2}$ stress by repairing degraded iron-sulfur clusters. Therefore, we hypothesize that the Hr protein has the same function as YtfE in repairing damage to iron-sulfur clusters and potentially by donating iron to iron-sulfur clusters (Nobre et al., 2014).

\section{ACKNOWLEDGMENTS}

Research supported by grants from the Chinese National Natural Science Foundation (under contract \#31502194), and the Science and Technology Program of Xiamen Southern Oceanographic Center (under contracts \#14CZP032HJ06 and \#14PYY050SF03). We gratefully acknowledge Prof. Nie and Dr. Y. Huang for providing some of the strains and plasmids used in this study. 


\section{Conflicts of interest}

The authors declare no conflicts of interest.

\section{REFERENCES}

Alfadda AA and Sallam RM (2012). Reactive oxygen species in health and disease. J. Biomed. Biotechnol. 2012: 936486. http://dx.doi.org/10.1155/2012/936486

Bailly X, Vanin S, Chabasse C, Mizuguchi K, et al. (2008). A phylogenomic profile of hemerythrins, the nonheme diiron binding respiratory proteins. BMC Evol. Biol. 8: 244. http://dx.doi.org/10.1186/1471-2148-8-244

Baumgartner WA, Dubytska L, Rogge ML, Mottram PJ, et al. (2014). Modulation of vacuolar $\mathrm{pH}$ is required for replication of Edwardsiella ictaluri in channel catfish macrophages. Infect. Immun. 82: 2329-2336. http://dx.doi.org/10.1128/ $\underline{\text { IAI.01616-13 }}$

Beinert H, Holm RH and Münck E (1997). Iron-sulfur clusters: nature's modular, multipurpose structures. Science 277: 653-659. http://dx.doi.org/10.1126/science.277.5326.653

Chao CM, Lai CC, Tang HJ, Ko WC, et al. (2013). Skin and soft-tissue infections caused by Aeromonas species. Eur. J. Clin. Microbiol. Infect. Dis. 32: 543-547. http://dx.doi.org/10.1007/s10096-012-1771-y

De Herdt P, Haesebrouck F, Charlier G, Ducatelle R, et al. (1995). Intracellular survival and multiplication of virulent and less virulent strains of Streptococcus bovis in pigeon macrophages. Vet. Microbiol. 45: 157-169. http://dx.doi. org/10.1016/0378-1135(95)00035-9

do Vale A, Marques F and Silva MT (2003). Apoptosis of sea bass (Dicentrarchus labrax L.) neutrophils and macrophages induced by experimental infection with Photobacterium damselae subsp. piscicida. Fish Shellfish Immunol. 15: 129144.http://dx.doi.org/10.1016/S1050-4648(02)00144-4

Fang FC (2004). Antimicrobial reactive oxygen and nitrogen species: concepts and controversies. Nat. Rev. Microbiol. 2: 820-832.http://dx.doi.org/10.1038/nrmicro1004

Finlay BB and Falkow S (1997). Common themes in microbial pathogenicity revisited. Microbiol. Mol. Biol. Rev. 61: 136-169.

Forst CV (2010). Host-pathogen systems biology. In: Infectious Disease Informatics. Springer, New York, 123-147

French CE, Bell JM and Ward FB (2008). Diversity and distribution of hemerythrin-like proteins in prokaryotes. FEMS Microbiol. Lett. 279: 131-145. http://dx.doi.org/10.1111/j.1574-6968.2007.01011.x

Garcia-del Portillo F and Finlay BB (1995). The varied lifestyles of intracellular pathogens within eukaryotic vacuolar compartments. Trends Microbiol. 3: 373-380. http://dx.doi.org/10.1016/S0966-842X(00)88982-9

Green MR and Sambrook J (2012). Molecular cloning: a laboratory manual. Cold Spring Harbor Laboratory Press, New York.

Guo S (2006). The pathogenic bacteria identification and correlative immune studies in eels. Wuhan: Institute of Hydrobiology, Chinese Academy of Sciences.

Herrero M, de Lorenzo V and Timmis KN (1990). Transposon vectors containing non-antibiotic resistance selection markers for cloning and stable chromosomal insertion of foreign genes in gram-negative bacteria. J. Bacteriol. 172: 6557-6567.

Isaza CE, Silaghi-Dumitrescu R, Iyer RB, Kurtz DM Jr., et al. (2006). Structural basis for O2 sensing by the hemerythrinlike domain of a bacterial chemotaxis protein: substrate tunnel and fluxional $\mathrm{N}$ terminus. Biochemistry 45: 90239031.http://dx.doi.org/10.1021/bi0607812

Janda JM and Abbott SL (2010). The genus Aeromonas: taxonomy, pathogenicity, and infection. Clin. Microbiol. Rev. 23: 35-73. http://dx.doi.org/10.1128/CMR.00039-09

Johnson DC, Dean DR, Smith AD and Johnson MK (2005). Structure, function, and formation of biological iron-sulfur clusters. Аnпи. Rev. Biochem. 74: 247-281.http://dx.doi.org/10.1146/annurev.biochem.74.082803.133518

Justino MC, Almeida CC, Teixeira M and Saraiva LM (2007). Escherichia coli di-iron YtfE protein is necessary for the repair of stress-damaged iron-sulfur clusters. J. Biol. Chem. 282: 10352-10359. http://dx.doi.org/10.1074/jbc. $\underline{\mathrm{M} 610656200}$

Kumar Y and Valdivia RH (2009). Leading a sheltered life: intracellular pathogens and maintenance of vacuolar compartments. Cell Host Microbe 5: 593-601.http://dx.doi.org/10.1016/j.chom.2009.05.014

Larsen MH and Boesen HT (2001). Role of flagellum and chemotactic motility of Vibrio anguillarum for phagocytosis by and intracellular survival in fish macrophages. FEMS Microbiol. Lett. 203: 149-152. http://dx.doi. org/10.1111/j.1574-6968.2001.tb10833.x 
Liu D (2009). Molecular detection of foodborne pathogens. CRC Press, New York.

Mizoguchi TJ and Lippard SJ (1998). Synthetic models of the deoxy and oxy forms of the non-heme dioxygen-binding protein hemerythrin. J. Am. Chem. Soc. 120: 11022-11023. http://dx.doi.org/10.1021/ja982417z

Nobre LS, Garcia-Serres R, Todorovic S, Hildebrandt P, et al. (2014). Escherichia coli RIC is able to donate iron to ironsulfur clusters. PLoS One 9: e95222. http://dx.doi.org/10.1371/journal.pone.0095222

Qin Y, Lin G, Chen W, Huang B, et al. (2014). Flagellar motility contributes to the invasion and survival of Aeromonas hydrophila in Anguilla japonica macrophages. Fish Shellfish Immunol. 39: 273-279. http://dx.doi.org/10.1016/j. fsi.2014.05.016

Ramandeep, Hwang KW, Raje M, Kim KJ, et al. (2001). Vitreoscilla hemoglobin. Intracellular localization and binding to membranes. J. Biol. Chem. 276: 24781-24789. http://dx.doi.org/10.1074/jbc.M009808200

Rock JL and Nelson DR (2006). Identification and characterization of a hemolysin gene cluster in Vibrio anguillarum. Infect. Immun. 74: 2777-2786. http://dx.doi.org/10.1128/IAI.74.5.2777-2786.2006

Roop RM 2nd and Caswell CC (2013). Bacterial persistence: finding the "sweet spot". Cell Host Microbe 14: 119-120. http://dx.doi.org/10.1016/j.chom.2013.07.016

Ruiz JC and Bruick RK (2014). F-box and leucine-rich repeat protein 5 (FBXL5): sensing intracellular iron and oxygen. J. Inorg. Biochem. 133: 73-77. http://dx.doi.org/10.1016/j.jinorgbio.2014.01.015

Ryckaert J, Bossier P, D'Herde K, Diez-Fraile A, et al. (2010). Persistence of Yersinia ruckeri in trout macrophages. Fish Shellfish Immunol. 29: 648-655.http://dx.doi.org/10.1016/j.fsi.2010.06.009

Sano G, Takada Y, Goto S, Maruyama K, et al. (2007). Flagella facilitate escape of Salmonella from oncotic macrophages. J. Bacteriol. 189: 8224-8232. http://dx.doi.org/10.1128/JB.00898-07

Secombes CJ (1990). Isolation of salmonid macrophages and analysis of their killing activity. Tech. Fish Immunol. 1: 137-154.

Seider K, Heyken A, Lüttich A, Miramón P, et al. (2010). Interaction of pathogenic yeasts with phagocytes: survival, persistence and escape. Curr. Opin. Microbiol. 13: 392-400. http://dx.doi.org/10.1016/j.mib.2010.05.001

Semenza GL (2012). Hypoxia-inducible factors in physiology and medicine. Cell 148: 399-408. http://dx.doi.org/10.1016/j. cell.2012.01.021

Stenkamp RE (1994). Dioxygen and hemerythrin. Chem. Rev. 94: 715-726. http://dx.doi.org/10.1021/cr00027a008

Taabazuing CY, Hangasky JA and Knapp MJ (2014). Oxygen sensing strategies in mammals and bacteria. J. Inorg. Biochem. 133: 63-72.http://dx.doi.org/10.1016/j.jinorgbio.2013.12.010

Vine CE, Justino MC, Saraiva LM and Cole J (2010). Detection by whole genome microarrays of a spontaneous 126-gene deletion during construction of a ytfE mutant: confirmation that a ytfE mutation results in loss of repair of ironsulfur centres in proteins damaged by oxidative or nitrosative stress. J. Microbiol. Methods 81: 77-79. http://dx.doi. org/10.1016/j.mimet.2010.01.023

Wilson BA, Salyers AA, Whitt DD and Winkler ME (2011) Bacterial pathogenesis: a molecular approach. American Society for Microbiology (ASM) Press, Washington.

Yamamoto T, Hanawa T, Ogata S and Kamiya S (1996). Identification and characterization of the Yersinia enterocolitica gsrA gene, which protectively responds to intracellular stress induced by macrophage phagocytosis and to extracellular environmental stress. Infect. Immun. 64: 2980-2987. 